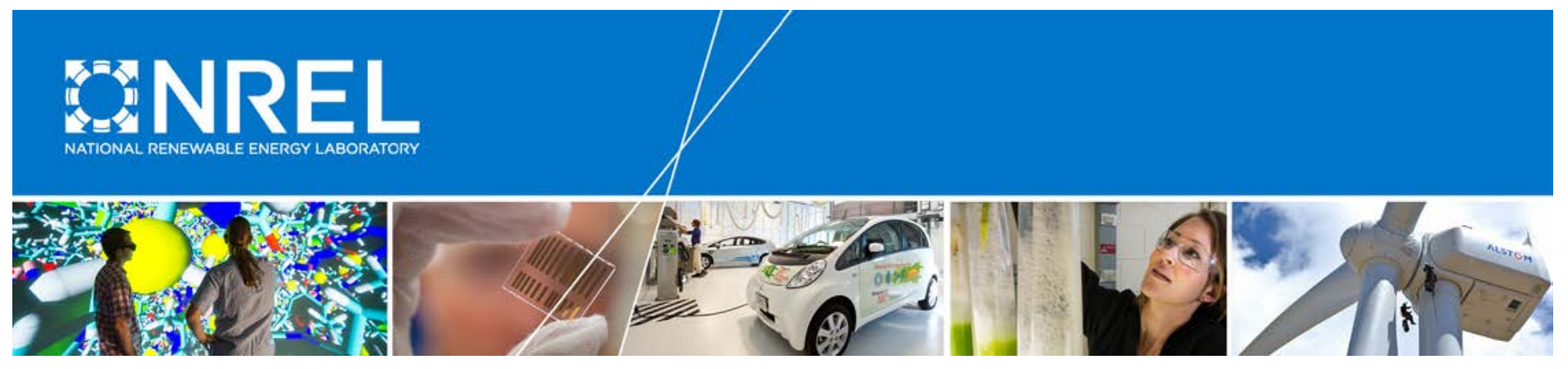

\title{
Material and Energy Efficiency: A Framework for Broader Analysis of Energy Use in the U.S. Economy
}

Colin McMillan

National Renewable Energy Laboratory

NREL is a national laboratory of the U.S. Department of Energy Office of Energy Efficiency \& Renewable Energy Operated by the Alliance for Sustainable Energy, LLC

This report is available at no cost from the National Renewable Energy Laboratory (NREL) at www.nrel.gov/publications.

Technical Report

NREL/TP-6A20-70609

June 2018 


\section{Material and Energy Efficiency: A Framework for Broader Analysis of Energy Use in the U.S. Economy}

Colin McMillan

National Renewable Energy Laboratory

\section{Suggested Citation}

McMillan, Colin. 2018. Material and Energy Efficiency: A Framework for Broader Analysis of Energy Use in the U.S. Economy. Golden, CO: National Renewable Energy Laboratory. NREL/TP-6A20-70609. https://www.nrel.gov/docs/fy180sti/70609.pdf.

NREL is a national laboratory of the U.S. Department of Energy Office of Energy Efficiency \& Renewable Energy Operated by the Alliance for Sustainable Energy, LLC

This report is available at no cost from the National Renewable Energy Laboratory (NREL) at www.nrel.gov/publications.

National Renewable Energy Laboratory 15013 Denver West Parkway Golden, CO 80401

303-275-3000 • www.nrel.gov

\section{Technical Report}

NREL/TP-6A20-70609

June 2018

Contract No. DE-AC36-08GO28308 


\section{NOTICE}

This work was authored by the National Renewable Energy Laboratory, operated by Alliance for Sustainable Energy, LLC, for the U.S. Department of Energy (DOE) under Contract No. DE-AC36-08G028308. Funding provided by U.S. Department of Energy Office of Energy Efficiency and Renewable Energy Office of Strategic Programs. The views expressed in the article do not necessarily represent the views of the DOE or the U.S. Government.

This report is available at no cost from the National Renewable Energy Laboratory (NREL) at www.nrel.gov/publications.

U.S. Department of Energy (DOE) reports produced after 1991 and a growing number of pre-1991 documents are available free via www.OSTI.gov.

Cover Photos by Dennis Schroeder: (left to right) NREL 26173, NREL 18302, NREL 19758, NREL 29642, NREL 19795.

NREL prints on paper that contains recycled content. 


\section{Preface}

This report, funded by the U.S. Department of Energy's (DOE) Office of Energy Efficiency and Renewable Energy (EERE) Strategic Programs, describes the results of a scoping study that explores the existing literature and approaches to the analysis of material efficiency in the consideration of broader energy use reduction strategies. Conventional energy efficiency analysis has been primarily concerned with exploring the potential to reduce energy consumption at its point of use in buildings, industry, and transportation. This report explores a complementary and more expansive analysis framework that also considers the energy embodied in materials and strategies and technologies that reduce raw material production while maintaining the highest-value function and use of materials. This proposed material and energy efficiency analysis framework suggests an approach and supporting tool to identify and assess the energy reduction potential of material efficiency strategies and technologies. The strategies that could emerge from this type of analysis represent generally unexplored opportunities to reduce the use of energy and other resources (e.g., water), and to reduce pollutant emissions.

This study contributes to a considerable body of analysis work at NREL that explores the energy reduction potential of energy efficiency technologies, along with related research and development, demonstration and deployment activities, policies, and associated impacts to the future evolution and operation of the U.S. energy system. 


\section{Acknowledgments}

The author thanks multiple reviewers for their helpful comments and technical review of this document. Reviewers included Steve Capanna, Sam Baldwin, Brian Walker, Ookie Ma, Joe Cresko, and Rudy Kahsar of the U.S. Department of Energy (DOE); Troy Hawkins of Eastern Research Group; and Gian Porro, Rebecca Hanes, and David Keyser of the National Renewable Energy Laboratory. We also thank Mike Meshek for editorial support. The author is grateful to Steve Capanna of DOE's Office of Strategic Programs in the Office of Energy Efficiency and Renewable Energy for his support of this study. This research was funded by the U.S. DOE under contract number DE-AC36-08GO28308. Any errors or omissions are the sole responsibility of the author. 


\section{Nomenclature or List of Acronyms}

BEA

BITES

Btu

DOE

EERE

EIA

EPR

IO

MFI

MRIO

NREL

PCE

USEEIO
Bureau of Economic Analysis

Buildings, Industry and Transportation Scenarios Tool

British thermal unit

U.S. Department of Energy

Office of Energy Efficiency and Renewable Energy

U.S. Energy Information Administration

extended producer responsibility

input-output

Materials Flows through Industry (tool)

multi-region input-output model

National Renewable Energy Laboratory

personal consumption expenditures

U.S. Environmentally Extended Input-Output (model) 


\section{Executive Summary}

Energy efficiency analysis has focused predominantly on reducing energy at its point of use by individual components, processes, or products. Efforts to address the energy embodied in materials through strategies and technologies that reduce raw material production and usewhile maintaining the function of those materials-offer a complementary and expansive approach to traditional energy efficiency analysis.

Developing a standardized U.S. framework to analyze the energy embodied in products and their materials may:

- Provide a more complete view of how energy is used throughout the economy, given that energy embodied in imports is not calculated in national energy statistics, yet has been estimated to account for over one-quarter of U.S. energy use (Lenzen et al. 2012, 2013)

- Enable a wider array of strategies and technologies for reducing the amount of energy the economy requires, which may double the potential to reduce energy use relative to energy efficiency strategies alone (Cooper et al. 2017).

Material efficiency falls under the concept of a circular economy, which refers to a system of production and consumption characterized by closed loops of materials and energy flows. As depicted in Figure ES-1, the circular economy would reduce natural resource consumption by reusing materials throughout the product life, unlike the typical modern "linear" economy that processes natural resources into finished products that are ultimately disposed as waste. Calls to adopt circular economy principles have come from national governments, intergovernmental organizations, and private companies.

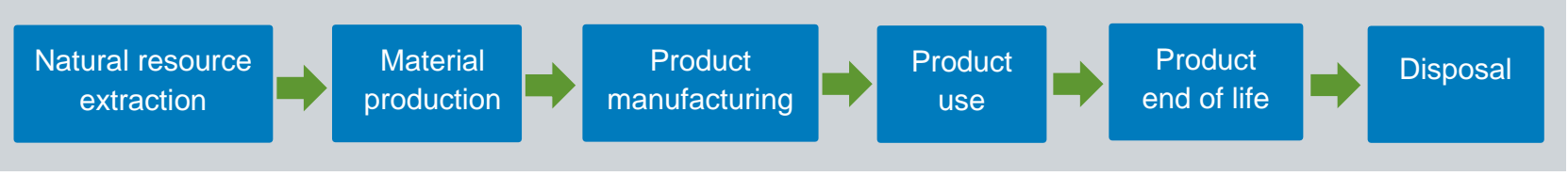

(a)

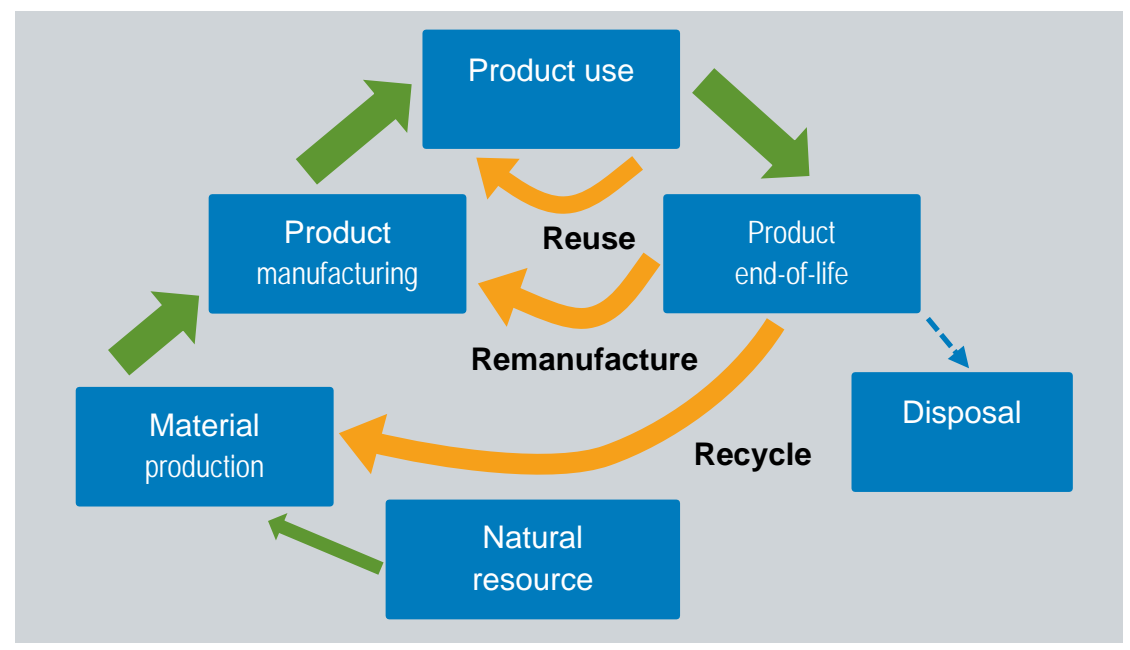

(b)

Figure ES-1. Linear (a) and circular (b) economies 
As opposed to strategies to increase energy efficiency, which may not result in absolute reductions in energy use, material efficiency strategies ultimately seek a reduction in the unnecessary production of new materials and products, and the resulting decrease in absolute energy use. The large energy intensity of material production industries and their existing achievements with incrementally improving energy efficiency indicates the importance of material efficiency strategies (Allwood et al. 2013). This report mentions six general material efficiency strategies identified by Allwood et al. (2011), which can be organized into three categories that either:

- Directly reduce material production (i.e., improved material yield ratio and designing products with less material)

- Avoid disposal and recycling (i.e., longer-lasting products, component reuse, and modularization and remanufacturing)

- $\quad$ Substitute for a less energy-intensive material (i.e., material substitution).

These strategies are parameterized in a material efficiency identity for the proposed material and energy efficiency analysis framework, described below.

The conventional focus on assessing energy efficiency potential at the point of energy use may mean novel policy and technology options that could reduce the accumulated use of energy, raw materials, criteria pollutants, or other emissions to the environment across supply chains are overlooked. China, several European Union (EU) member states, as well as the EU itself are developing ambitious plans to increase the materials efficiency of their economies. Notable policy approaches include developing and deploying resource- and energy-efficient production and processing technologies, integrating resource conservation into standardization, and boosting innovation and competitiveness by strengthening technical support for companies to improve efficiency (National People’s Congress Standing Committee 2013; European Commission 2011).

The U.S. Department of Energy (DOE) energy analysis community currently lacks analytical tools that are appropriate for (1) estimating on an industry and economy-wide basis energy efficiency potential achieved through material efficiency strategies and (2) evaluating how such new strategies may complement existing energy efficiency efforts. The goal of this report is to describe a standardized analysis framework that would enable calculation of embodied and direct energy and the estimation of energy reduction potential achieved through changes in material use. The proposed framework meets this functionality by spanning the entire U.S. economy, including international trade flows; capturing material and energy use in products and services from raw material extraction to disposal maintaining material and energy balances; and adjusting dynamically to absolute and relative changes in materials and energy use.

The proposed material and energy efficiency analysis framework could be used to provide a baseline of the energy embodied and directly used in consumption and production of goods and services by the U.S. economy. This baseline could then be used to identify embodied energy hotspots, which may reveal energy-intensive areas of the economy that have historically not been a focus of efficiency efforts. The framework is also designed to estimate the technical potential of technologies that reduce energy use along multiple steps of a supply chain, such as additive manufacturing of lighter-weight and less materially-intensive transportation equipment components. 
The framework expands the capabilities of an existing suite of tools and analysis within the federal government. A very small subset of these tools and analysis includes the Materials Flows through Industry (MFI) Tool (National Renewable Energy Laboratory 2017; Hanes and Carpenter 2017); the GREET model (Argonne National Laboratory 2017); the Buildings, Industry, and Transportation Scenarios (BITES) Tool (National Renewable Energy Laboratory n.d.); and Scout (U.S. Department of Energy Building Technologies Office 2017), which are used at DOE.

The framework is composed of two main elements:

1. A dynamic hybrid input-output (IO) model. The hybrid aspect of the IO model is its use of physical units (e.g., British thermal units [Btu] and tons) to define recipes for energy and material flows in combination with monetary units used for other industries. By defining material and energy flows in physical units, the hybrid model can satisfy physical conservation conditions that are not necessarily met when using a purely monetary IO model. The model is also dynamic in that it allows adjustments to the amount of materials and energy used by industries within the economy. Traditional IO models are static and assume fixed relationships of transactions between industries; a dynamic approach allows these relationships to change over a given time step.

2. A material energy identity. The material energy identity, acts as a way of identifying and parameterizing energy efficiency strategies and the six material efficiency strategies identified above. The material energy identity defines the amount of energy used in the production of a material as a function of material demand, the fraction of primary, recycled, or reused material, and their energy intensities. The potential effects of individual or combined material efficiency and energy efficiency strategies are then implemented and analyzed in the hybrid IO model

This report also provides an example of an application of the proposed framework to (1) illustrate the concept of reducing energy use through changes to material efficiency and (2) demonstrate the use of IO analysis. A simple example was chosen to demonstrate the concept, as the goals of this report are to establish the importance of considering the energy embodied in materials and proposing an analytical framework that can estimate the energy reduction potential of material efficiency strategies. Much more detailed and analytically satisfying examples that reflect the complexity of real-world material flows could be developed by implementing the proposed framework. 


\section{Table of Contents}

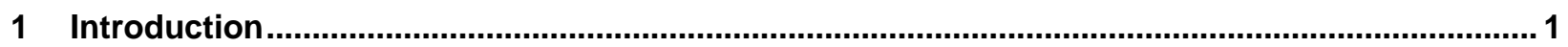

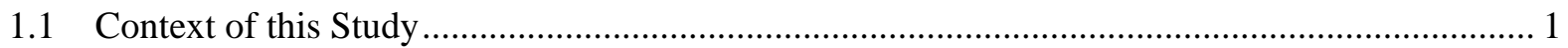

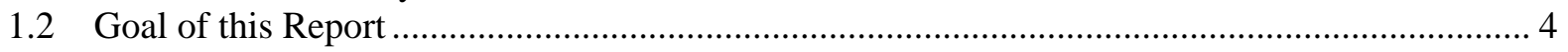

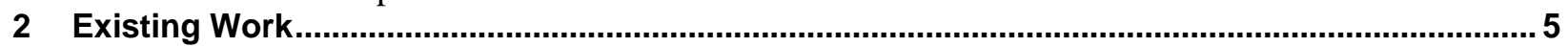

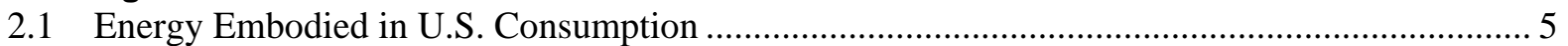

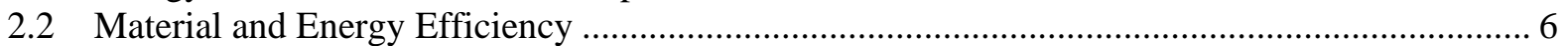

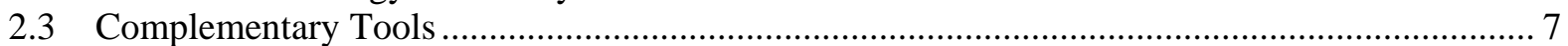

3 Examples of Material Efficiency Policies and Strategies .......................................................... 8

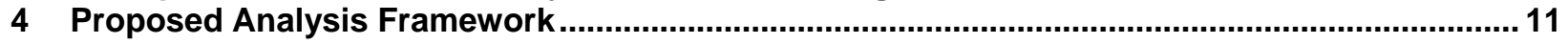

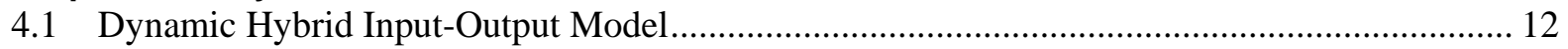

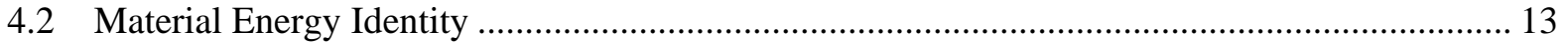

4.3 Advantages and Limitations of Analysis Framework ............................................................. 14

5 Analyzing Material and Energy Efficiency Strategies-an Example Application .......................16

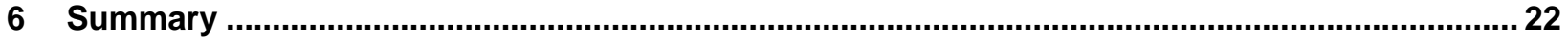

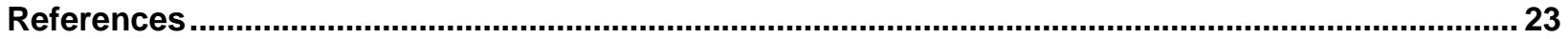

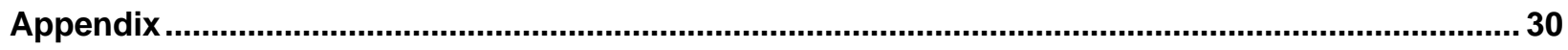




\section{List of Figures}

Figure ES-1. Linear (a) and circular (b) economies............................................................................... vi

Figure 1. Notional flows of primary energy to ultimate service demand drivers ........................................ 2

Figure 2. Linear (a) and circular (b) economies........................................................................................ 3

\section{List of Tables}

Table 1. Summary of Energy Efficiency and Material Efficiency Strategy Categories ........................... 14

Table 2. Personal Consumption Expenditures (PCE) Bridge, 2007 .......................................................... 17

Table 3. Energy and Material Direct Requirements for “Soft Drink and Ice Manufacturing," 2007 (\$/\$) 18

Table 4. Energy and Material Total Requirements for Soft Drink and Ice Manufacturing, 2007 (\$/\$) ..... 19

Table 5. Direct and Total Requirements for End-Use Product Demand Associated with "Soft Drink and

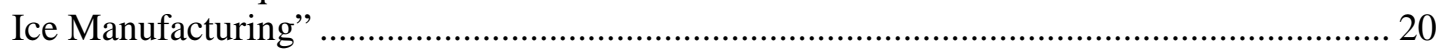

Table 6. Material and Energy Efficiency Potential Analysis: Notional Values........................................ 21 


\section{Introduction}

Overlooking life cycle energy efficiency opportunities, including reducing the energy embodied in materials may miss an energy reduction potential that is equivalent to the magnitude of traditionally defined energy efficiency (Cooper et al. 2017). The material efficiency approach to energy use, which explicitly traces energy throughout the supply chain (or, equivalently, the product life cycle), is particularly important in modern, developed economies that rely on imported basic materials and products. The energy embodied in these imported goods and services were estimated to account for over one-quarter of U.S. energy use (Lenzen et al. 2012, 2013). Additionally, energy efficiency alone has been shown to be insufficient for meeting global emissions reduction targets for materials production given anticipated future materials demand (Milford et al. 2013). The goal of this report is to describe a standardized analysis framework that would enable calculation of embodied and direct energy and the estimation of energy reduction potential achieved through changes in material use.

\subsection{Context of this Study}

Figure 1 presents a notional example of flows of primary energy embodied in demand for final services. This method connects energy use to ultimate drivers of demand, namely structure, thermal comfort, and subsistence, as opposed to only disaggregating energy carriers by end use (e.g., electric motor, natural gas burner) like in end use surveys (Energy Information Administration 2017) or by major economic sector in state and national energy statistic sources. The demand for structure encompasses the production of materials for the built environment as well as for products; in other words, this represents the energy embodied in materials. By focusing on direct energy use and not considering the energy embodied in materials, energy efficiency analysis in its most common form neglects potentially significant opportunities to improve life cycle energy efficiency. For instance, the growing use of recycled aluminum is responsible for nearly two-thirds of the decrease in aluminum production energy intensity from 1960 to 2003 (Choate and Green 2003). 


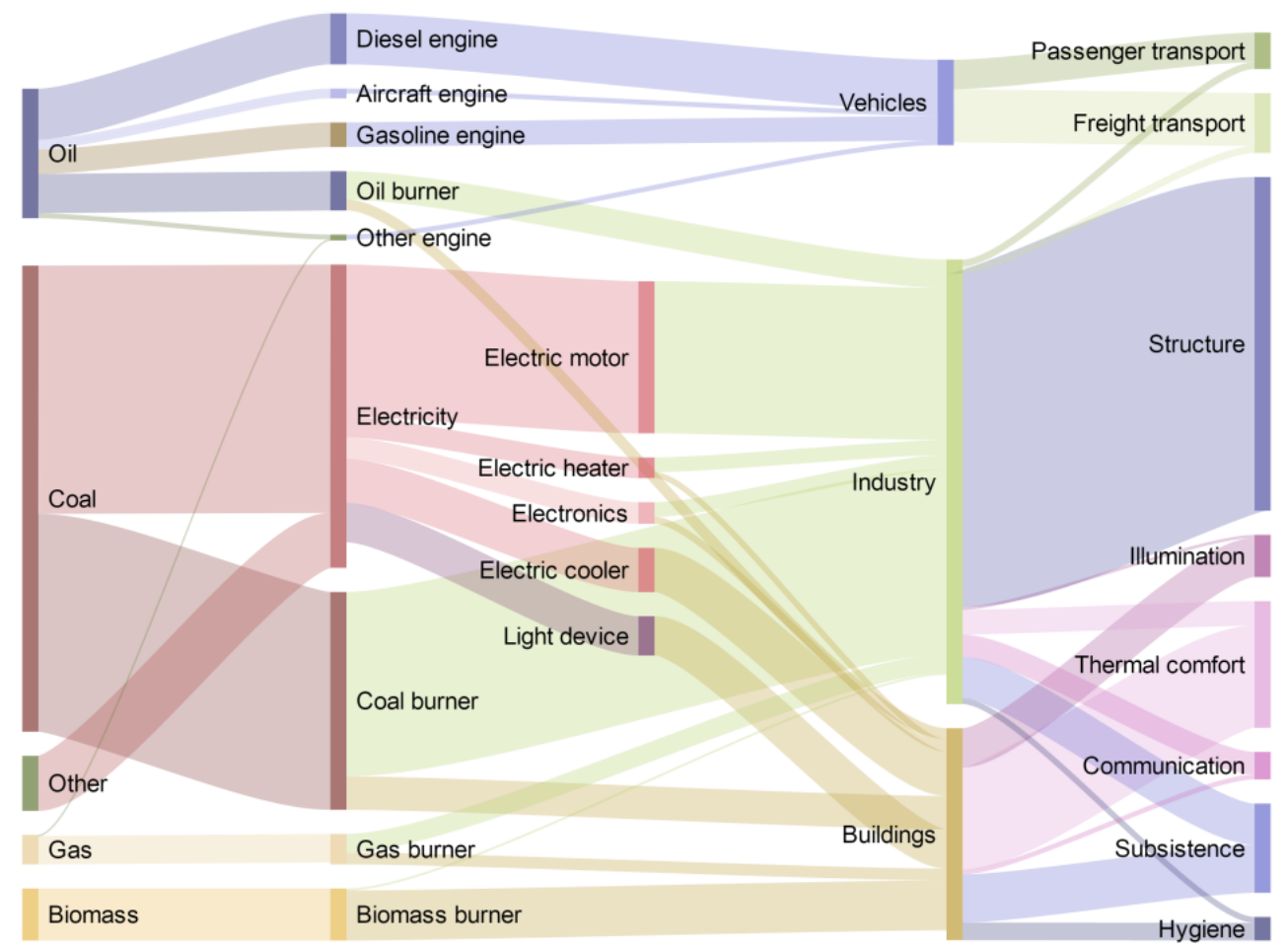

Figure 1. Notional flows of primary energy to ultimate service demand drivers

(adapted from Ma et al. 2012. Other includes nuclear and non-combustion renewables)

Energy efficiency analysis has predominantly focused on reducing energy at its point of use by individual components, processes, or products. Examples of this type of analysis include energy efficiency potential studies (e.g., Holmes and Mullen-Trento 2017; EPRI 2017; U.S. Department of Energy 2017, 2016). However, exceptions exist that define efficiency more broadly (e.g., Laitner et al. 2012). Although the interactions between aggregated components and products are sometimes considered, such as the case of the GREET model (Argonne National Laboratory 2017), energy use is typically viewed in isolation along each stage of a product's supply chain or life cycle. ${ }^{1}$

Like energy efficiency analysis, existing energy efficiency programs-including associated technology research and development and deployment activities supported by the U.S. Department of Energy (DOE) - are primarily focused on energy at the point of use in buildings, industrial processes, and transportation. For example, DOE is responsible for implementing minimum energy use requirements for appliances and equipment; these standards cover approximately $90 \%$ of residential energy use, $60 \%$ of commercial energy use, and $30 \%$ of industrial energy use (U.S. Department of Energy 2017a). ${ }^{2}$ However, targeting only the product use phase may not reduce total life cycle energy and may result in unintentional and undesirable

\footnotetext{
${ }^{1}$ A product life cycle can be defined as the sequential stages that are required to extract, convert, and otherwise process natural resources into finished products that used until they are ultimately retired at their end of life.

2 The appliance standards process does include a calculation of "upstream fuel-cycle" emissions in its air emissions analysis. See, for example, U.S. Department of Energy (2010).
} 
effects. For instance, it may take at least 33 years to pay back the environmental costs of replacing a notebook computer with one that is $10 \%$ more efficient because production-phase environmental emissions dominate the smaller use-phase emissions (Prakash et al. 2012).

DOE's energy efficiency focus, however, expanded with the announcement of the REMADE Institute, whose aim is to enable early-stage applied research and development for reducing the embodied energy of materials production and processing (Sustainable Manufacturing Innovation Alliance 2017). Additionally, the multi-year program plan of DOE's Advanced Manufacturing Office specifically states that life cycle impacts are key considerations for the office (U.S. Department of Energy Advanced Manufacturing Office 2016). These more recent developments join existing life cycle tools such as the GREET model (Argonne National Laboratory 2017) and the Materials Flows through Industry (MFI) tool (Hanes and Carpenter 2017).

Efforts to address the energy embodied in materials through strategies and technologies that reduce raw material production - while maintaining the highest-value function and use of materials - offer a complementary and expansive approach to traditional energy efficiency analysis. Material efficiency falls under of the concept of a circular economy, which refers to a system of production and consumption characterized by closed loops of materials and energy flows. Unlike the typical modern "linear" economy that processes natural resources into finished products that are ultimately disposed as waste, the circular economy would reduce natural resource consumption by reusing materials. General depictions of a linear economy and a circular economy are presented as Figure 2.

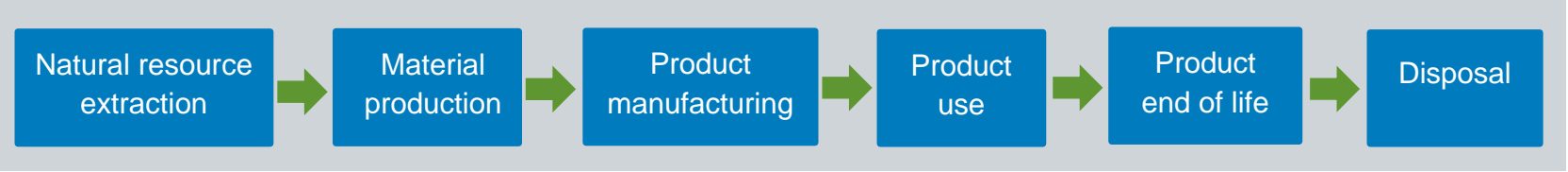

(a)

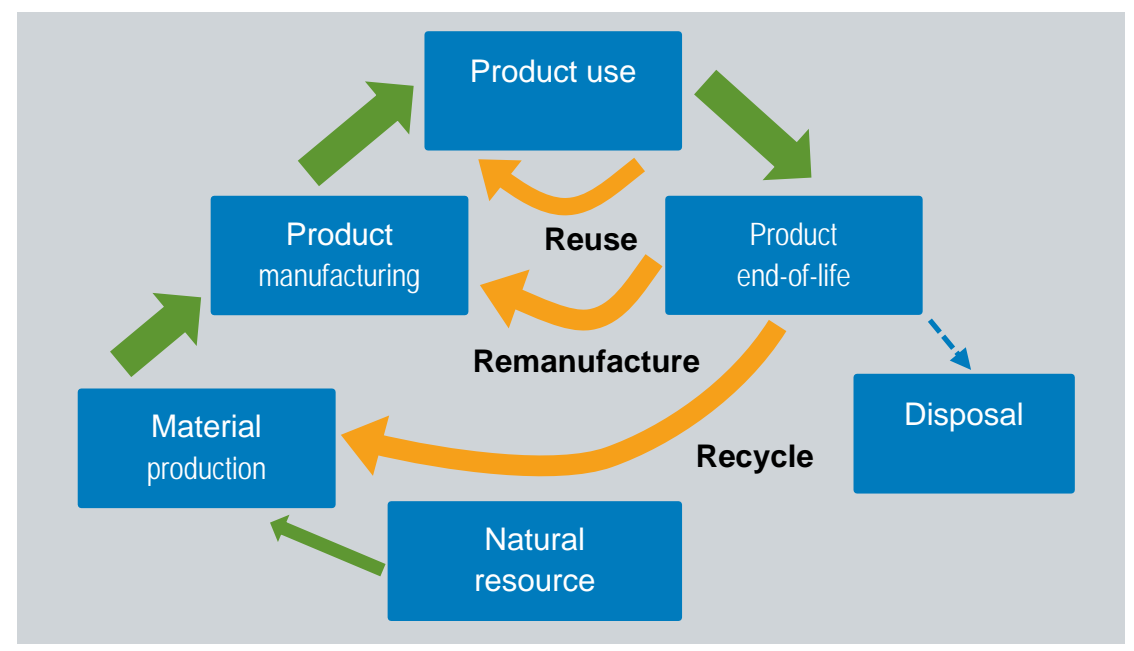

(b)

Figure 2. Linear (a) and circular (b) economies 
Production of five materials (steel, cement, plastic, aluminum, and paper) constitutes 13\% of global energy use and 20\% of global greenhouse gas emissions (Gutowski 2014). However, further improvements to energy efficiency for certain current material production technologies may be limited, and changes to materials use in these cases would be needed to achieve global pollution mitigation targets (Allwood et al. 2013; Allwood, Cullen, and Milford 2010). The European Union (EU) has begun formalizing materials efficiency strategies through the publication of a roadmap on resource efficiency (European Commission 2011) and an action plan for the circular economy (European Commission 2015b). Materials efficiency has also been identified as a component of deep decarbonization pathways by the EU and its individual member states (WSP Parsons Brinckerhoff and DNV-GL 2015; Wortler et al. 2013). A detailed discussion of material efficiency policies is provided in Section 3.

Accounting of international trade of goods and services represents a critical component of analyzing embodied energy. The EIA's production-focused energy accounting framework currently does not capture the energy embodied in imports and exports of materials, products, and services outside of trade in fossil fuels. Studies of the U.S. economy indicate that imported goods and services accounted for $60 \%$ of raw material consumption in 2008 (Wiedmann et al. 2015), 26\% of energy use in 2005 (Lenzen et al. 2012 and Lenzen et al. 2013) ${ }^{3}$, and 30\% of greenhouse gas emissions in 2004 (Weber and Matthews 2007).

\subsection{Goal of this Report}

The conventional focus on assessing energy efficiency potential at the point of energy use may underestimate the overall energy efficiency potential of the U.S. economy, and may mean novel policy and technology options that could reduce criteria pollutants and other emissions to the environment are overlooked. The DOE energy analysis community currently lacks analytical tools that are appropriate for (1) estimating on an industry and economy-wide basis energy efficiency potential achieved through material efficiency strategies or (2) evaluating how these new strategies may complement existing energy efficiency efforts. Several existing tools used for energy efficiency analysis by DOE (e.g., Scout [U.S. Department of Energy Building Technologies Office 2017], National Energy Modeling System Model [NEMS] [EIA 2009], and Buildings, Industry, Transportation, and Electricity Scenarios Tool [BITES] [National Renewable Energy Laboratory n.d.]) are concerned with energy at the point of use in equipment, appliances, and other products.

The goal of this report is to describe a standardized analysis framework that would enable the calculation of embodied and direct energy and the estimation of energy reduction potential achieved through changes in material use. The proposed framework meets this functionality by spanning the entire U.S. economy, including international trade flows; capturing material and energy use in products and services from raw material extraction to disposal; maintaining material and energy balances; and adjusting dynamically to absolute and relative changes in materials and energy use.

3 The embodied energy in net imports (i.e., imports less exports) in 1984 was estimated as 3\% of total energy (Williams, Larson, and Ross 1987). 


\section{Existing Work}

\subsection{Energy Embodied in U.S. Consumption}

Estimates of energy embodied in the U.S. economy were first developed in the 1970s. These early studies were conducted from the perspective of household consumption of goods and services. Using an economic input-output (IO) framework developed by Leontief (1936), Herendeen and Tanaka (1976) estimate household energy use in 1960-1961 and note that "the average household consumes more energy indirectly through the purchase of goods and services than directly through the purchase of energy itself” (p. 165).

Analyses of energy embodied in household consumption do not necessarily account for the energy impacts of foreign trade. One area that has received considerable attention, however, is the estimation of consumption-based national greenhouse gas accounting (e.g., Davis and Caldeira [2010]), which could be considered a proxy for primary energy use.

Another proxy is to examine the mass of materials used in an economy. Recent analysis using a multi-regional IO model (MRIO) ${ }^{4}$ revealed the importance of analyzing the materials embodied in the international trade, not just the amount of materials directly ${ }^{5}$ traded. Wiedmann et al. (2015) find that $41 \%$ of 70 billion metric tons of raw materials used globally in 2008 was indirectly associated with international trade flows. The United States was found to be the largest importer of raw materials (both direct and indirect) and the country with the third-largest materials footprint ${ }^{6}$ per capita at approximately 27 metric tons per person. Based on data from Wiedmann et al. (2015), for example, the U.S. per capita materials footprint is roughly $16 \%$ smaller than that of Canada and 26\% larger than that of Germany.

Additionally, analysis using a combination of material flow analysis and MRIO models has shown that the United States is using an increasing amount of iron ore and bauxite for every dollar of gross domestic product (GDP). From 1990 to 2008, resource productivity (measured as GDP/ton) of iron ore and bauxite decreased by roughly $40 \%$ and $57 \%$ respectively (Wiedmann, Schandl, and Moran 2014).

\footnotetext{
${ }^{4}$ A multiregional input-output (MRIO) model accounts for interregional industry transactions and unique intraregional industry transactions. A review of MRIOs used for resource accounting and consumption-based emissions accounting is provided by Wiedmann (2009).

${ }^{5}$ Direct use of materials or energy occurs at a single stage in a product supply chain or life cycle; indirect use is the sum of materials or energy use in all prior supply chain or life cycle stages.

${ }^{6}$ A material footprint represents the total amount of material used along the entire life cycle or production chain of a product, from raw material extraction to final disposal.
} 


\subsection{Material and Energy Efficiency}

Several examples of existing analysis formally link materials efficiency and energy efficiency. Unlike the proposed material and energy efficiency analysis framework described in the subsequent section, however, these examples look at materials use in aggregate and do not examine use by final consumer demand. Additionally, the analyses performed on the country level do not include materials and energy embodied in the net import of goods and services, which is a crucial consideration, given the significance of international trade.

For example, Worrell et al. (1995) estimate the technical potential of materials efficiency to reduce energy consumption for plastic packaging in the Netherlands by $31 \%$. The authors first estimate the consumption of plastics by packaging type and then estimate the potential material and energy savings and qualitative range of capital costs associated with relevant materials efficiency strategies. The authors note the increased difficulty of applying a similar approach to materials that have longer lifetimes. In another example of linking energy and material efficiency, Worrell et al. (1997) examine trends and existing analysis of the use of steel, cement and concrete, pulp and paper, plastics, and fertilizers, and they conclude "integrated assessments of the energy/materials-system suggest that energy savings can be achieved at lower costs through combined energy and material efficiency approaches” (p. 76).

Milford et al. (2011) use material flow analysis models to find that the energy benefits of reducing scrap rates in global steel and aluminum production are similar in magnitude to those of implementing best available energy efficiency technologies. Milford et al. (2013) use a dynamic stock and flow model of the global iron and steel industry to conclude aggressive energy efficiency efforts alone may reduce greenhouse gas emissions by only $20 \%$ relative to business as usual by 2050; more significant reductions become possible with the introduction of materials efficiency strategies. Gilbert et al. (2017) find that materials efficiency has the potential to reduce the energy associated with producing a steel ship hull by nearly $30 \%$.

More recently, analyses combining energy and material efficiency analysis have taken a lifecycle and whole-economy focus. Cooper et al. (2017) find in analysis of the global, EU-27, and United Kingdom (UK) economies that circular economy strategies (i.e., reducing the need for inputs to produce products by reducing material content of products, reducing material losses, substituting materials, and enhancing recycling; and reducing the need for products by increasing use intensity, increasing longevity, and extending lifetimes) have the potential to reduce energy use by amounts equivalent to estimated energy efficiency potentials. Energy reductions for the EU-27 and UK are between 5\%-9\% and 4\%-6\%, respectively. Because they account for the energy embodied in trade, the authors estimate additional, global energy reductions of $1 \%-3 \%$ for strategies implemented within the EU-27 and UK. The authors also estimate that in the UK strategies for reducing the need for products result in energy savings nearly twice as large as strategies for reducing inputs to produce products. This is the result of the UK's reliance on imports, as well as a lower relevance for strategies that reduce inputs to production for UKmanufactured products.

In addition to the energy and environmental impacts of material efficiency, analysis has addressed economic impacts. Walz (2011) estimates the German employment impacts of five material efficiency strategies and finds that each strategy results in a net positive impact for total employment. The total employment figure, however, hides substantial variation in the effects for 
individual economic sectors. Cooper et al. (2016) examine the net change in direct and indirect employment for construction steel reuse and car sharing in the United Kingdom. Their low case assumptions result in negligible impacts to employment, but their high case assumptions result in net changes of between 3,000 and 3,500 jobs.

\subsection{Complementary Tools}

The material and energy efficiency analysis framework proposed here expands the capabilities of an existing suite of tools and analysis within the federal government. A very small subset of these tools and analysis includes the Materials Flows through Industry (MFI) tool (National Renewable Energy Laboratory 2017; Hanes and Carpenter 2017), the BITES tool (National Renewable Energy Laboratory n.d.), and Scout (U.S. Department of Energy Building Technologies Office 2017) used at DOE. Other agencies, such as the Defense Logistics Agency of the Department of Defense (Henry 1997), the National Institute of Standards and Technology (National Institute of Standards and Technology n.d.), the U.S. Department of Commerce (U.S. Department of Commerce and Economics and Statistics Administration 2010), and the U.S. Environmental Protection Agency (EPA) (Singh et al. 2017; Yang et al. 2017) have also developed IO models and analysis. Notable examples of relevant U.S. IO models outside of federal government include the Comprehensive Data Archive (CEDA) (Industrial Ecology Research Services (IERS) 2017) and Open IO (The Sustainability Consortium n.d.). Note, however, that the Open IO website was no longer available as of May 2018. 


\section{Examples of Material Efficiency Policies and Strategies}

Perhaps no other country is developing as ambitious plans for materials efficiency as China is (Mathews and Tan 2016). Under the Circular Economy Promotion Law of the People's Republic of China, China will, for example, establish a circular economy statistics system, establish and improve a product labeling system for resource consumption, support research and development for technology that supports the circular economy, and encourage waste energy recovery in industrial parks (National People's Congress Standing Committee 2013). More recently, the $13^{\text {th }}$ Five-Year Plan calls for coordinating industry layouts based on material flows, establishing industry-agriculture circular economy demonstration zones, facilitating the recovery and reuse of urban waste, and implementing an extended producer responsibility system (Central Committee of the Communist Party of China 2016).

The EU and its individual member states have been sources of many recent efforts to explore policies that are directly and indirectly related to material efficiency. Three EU countriesAustria, Finland, and Germany — have national strategies for material efficiency (European Environment Agency 2016). The German Resource Efficiency Program identifies 20 approaches to increasing material efficiency that span the entire product value chain, from securing a sustainable raw material supply to enhancing resource-efficient close-cycle management (Federal Ministry for the Environment, Nature Conservation, Building and Nuclear Safety 2012). Notable approaches include developing and deploying resource- and energy-efficient production and processing technologies, integrating resource conservation into standardization, and boosting innovation and competitiveness by strengthening technical support for companies to improve efficiency.

The European Commission has established a roadmap on resource efficiency (European Commission 2011), an action plan for the circular economy (European Commission 2015b), and the Ecodesign Directive, which covers energy-using products (Directive 2005/32/EC of the European Parliament and of the Council 2005). Among other policy actions, the resource efficiency roadmap calls for:

- Establishing a common methodology to assess the life cycle environmental performance of products, services, and companies

- Using the results of the methodology to improve the resource efficiency of products

- Creating public-private partnerships to pool research efforts on resource efficiency

- Identifying innovative financial instruments for resource efficiency (European Commission 2011). 
The European Commission's circular economy action plan includes actions to define quality standards for recycled raw materials, further develop the raw materials information system, ${ }^{7}$ and develop pre-demolition guidelines for the construction industry (European Commission 2015a). And, the Ecodesign Directive calls for product performance parameters that address the life cycle energy and material use of energy-using products (Directive 2005/32/EC of the European Parliament and of the Council 2005).

The EPA summarized opportunities and actions to improve resource efficiency based on discussion at a G7 Alliance on Resource Efficiency workshop (EPA 2016). These actions include using applied research and analysis to support innovative development of resource-efficient technologies; integrating end-of-life planning early in the product design process; and specifying resource-efficient public and private procurement (EPA Office of Land and Emergency Management 2016).

Söderholm and Tilton (2012) identify market failures (e.g., market prices that do not internalize environmental costs and the presence of asymmetric information) that may be suitable to correction using public policy instruments related to material efficiency. The authors state that it is not possible for policymakers to know which material efficiency policies will be the most promising and cost-effective, particularly because of the impacts of rapidly advancing technology; instead, Söderholm and Tilton identify the usefulness of a combined approach of investing in public research and development, and eliminating distortions in producer and consumer decision-making. Addressing the distortions present in recycling markets may be accomplished through an extended producer responsibility (EPR) system, which can combine a product tax or recycling subsidy with a disposal tax to incentivize the production of recyclable products and their collection for recycling (Walls 2003 in Söderholm and Tilton 2012).

The EU and its member states provide examples of national EPR policies, along with other policies related to materials efficiency. EPRs hold manufacturers responsible for their products after their end of life. EPRs have been implemented in many member states for batteries, vehicles, packaging, and electronics (BIO Intelligence Service 2014). A consortium of European research institutions has explored several policy instruments, such as product standards for reusability and recyclability; combined taxes on virgin materials, landfills, and waste incineration; feebate schemes based on environmental performance for selected product categories; and value-added-tax reduction for products and services with superior environmental performance ("Dynamix | Decoupling Growth from Resource Use and Its Environmental Impacts” n.d.). More recently, Sweden reduced the value-added-tax on repairs to bicycles, clothes, and shoes by $50 \%$ and now allows consumers to claim half of the labor costs of appliance repairs on their income taxes (Margolis 2017).

The private sector could adopt materials efficiency-related business models, such as providing a service rather than a physical product ("access and performance model”), recovering products at the end of their useful lives ("extending product value"), or providing long-lived products supported by high levels of customer service ("long life model”) (Bocken et al. 2016). Several

\footnotetext{
7 The raw materials information system is the European Commission's reference knowledge platform for nonagricultural, non-fuel primary and secondary materials (Eurpoean Commission 2017). It includes information on material flows, critical materials, and raw materials scoreboards.
} 
companies have already incorporated these strategies into their operations. Patagonia promotes to consumers the longevity and reparability of their outdoor apparel products as an alternative to new purchases ("Worn Wear: Better Than New - Patagonia.Com" 2016). When the Ford Motor Company introduced its aluminum-bodied F-150, it also created a closed-loop system for returning scrap aluminum generated during truck production to its aluminum material supplier (“Recycled Materials: Sustainability Report 2015/16: Ford Motor Company” 2016). Other companies have developed new, material-efficient production technologies. In 2012, Nike began selling a shoe produced using a weaving technology that is reported to reduce waste by about $60 \%$ relative to cutting and sewing shoes ("Nike Aims to Transform Manufacturing” 2016). 


\section{Proposed Analysis Framework}

The proposed analysis framework for material efficiency shifts focus from the traditional residential-commercial-industrial-transportation basis to a consumption basis where material and energy flows are tied to their use in goods and services. Using this new focus, available data and analytical methods enable the estimation of the economy's direct and indirect energy requirements. Although it is possible to expand the framework to include other significant sources of embodied energy, such as food, the initial analysis focus is on durable goods.

The goal of energy efficiency is to reduce the amount of energy required to provide an energy service, typically at its point of use. Focusing on the direct use of energy in this way may mean factors that contribute to overall system energy use are overlooked. Material production, product manufacturing, and consumer use are only portions of a larger system of activities (or "value chain") that begins with the extraction of natural resources and concludes with a product's end of life. By calculating embodied materials and energy, the analysis framework captures this system of activities and enables identification of a broader and potentially more significant menu of strategies and technologies to reduce energy use.

The proposed analytical framework is composed of two main elements:

- a dynamic hybrid IO model and

- a material energy identity.

Estimating the energy reduction potential of material efficiency strategies begins with quantifying the materials and energy embodied in final goods and services, which are used directly by the consumer and not in the production of other goods or services (i.e., intermediate goods). However, the composition and mass of the material content in products typically is unknown and difficult to obtain. The proposed method to overcome this limitation is to use economic IO tables, which represent general "recipes" of inputs used to produce economic output in monetary units. The most detailed economic IO data published by the U.S. Department of Commerce Bureau of Economic Analysis (BEA) provide interindustry transactions for nearly 400 commodities. IO data indicate the production and use of these commodities by industries in "make" and "use" tables, which form the basis for estimates of U.S. economy total direct and indirect use of commodities. The hybrid IO model defines recipes for material and energy flows in physical (e.g., Btu and tons) and monetary units. The model can be used to estimate the potential effects of energy and material efficiency strategies. Core mathematical aspects of the model are described in the Appendix. The second element of the analytical framework, the material energy identity, acts as a way of identifying and parameterizing energy and material efficiency strategies, which are then implemented and analyzed in the hybrid IO model.

The proposed analysis framework could be used to provide a baseline of the energy embodied and directly used in consumption and production of goods and services by the U.S. economy. This baseline could then be used to identify embodied energy hotspots, which may reveal energy-intensive areas of the economy that have historically not been a focus of efficiency efforts. The framework is also designed to estimate the technical potential of technologies that reduce energy use along multiple steps of a supply chain, such as additive manufacturing of lighter-weight and less materially-intensive transportation equipment components. 


\subsection{Dynamic Hybrid Input-Output Model}

Economic IO models were first used to examine the flows of energy within the U.S. economy and to estimate the energy embodied in household consumption in the 1970s. These early efforts were based on an approach that uses financial IO tables as they are published by BEA and direct energy coefficients that defined the amount of energy required to produce one dollar of output for each industrial sector. More recently, the publicly available Economic Input-Output Life Cycle Assessment (EIO-LCA) model was developed at Carnegie Mellon University; however, the model has not been updated from 2002 data. Most recently, EPA recently published its U.S. Environmentally Extended Input-Output (USEEIO) model, which provides monetary flows and associated data on emissions and resource use per dollar for 2013 (U.S. EPA Office of Research and Development 2017).

The economic IO approach has several limitations, such as the model "providing internally consistent results only when energy prices are the same across all consuming sectors for each energy type" (Miller and Blair 2009, p. 432). Although this approach continues to be used because of its relative ease of implementation, ${ }^{8}$ newer applications of energy IO analysis have overcome limitations of the traditional approach.

The contemporary IO analysis approach combines monetary and physical units to create a hybrid model. Hybrid economic-input tables are developed by replacing financial flow data with physical flow data for energy and materials produced and used by industries. In the hybrid model for energy, for instance, interindustry transactions between the energy-producing industries and the energy-using industries are defined in Btu and all other interindustry transactions are defined in dollars. This results in the direct requirements and total requirements matrices containing mixed units (Btu/Btu, Btu/\$, $\$ / B t u$, and $\$ / \$$ in the case of an energy hybrid IO model), as described in the Appendix. ${ }^{9}$

The proposed hybrid IO model requires energy, materials, and financial transactions data. With financial transactions data provided in the IO tables published by the BEA, most of the data collection and preparation efforts are associated with energy and materials flows. Sources for energy flow data include the EIA Monthly Energy Review, Manufacturing Energy Consumption Survey, and Commercial Building Energy Consumption Survey. World energy and financial IO data are available from the Eora MRIO database ("Eora MRIO Database” n.d.). The initial version of the proposed model would not differentiate between the source countries of imported goods and services and would not include transportation energy.

Another proposed change to traditional IO analysis is to introduce the capability of dynamic transactions and technical coefficients. Traditional IO models are static and assume fixed technical coefficients (the relationships of transactions between industries) ${ }^{10}$; a dynamic

\footnotetext{
${ }^{8}$ Vendries Algarin et al. (2016) analyze the impact of using heterogeneous prices instead of the assumption of homogenous prices on estimating greenhouse gas emissions from electricity use. They find that manufacturing sector emissions are more sensitive to the choice between economic and physical allocation.

${ }^{9}$ One alternative to the contemporary and hybrid approaches of incorporating physical units is to construct a correspondence matrix that defines the relationship between physical and monetary products (Ewing et al. 2012).

${ }^{10}$ This means an industry uses the same ratio of inputs per output regardless of how much or how little output it produces.
} 
approach would allow the relationships of transactions between industries to change over a given time step, which would be represented by changes to technical coefficients. In order to overcome the limitation of fixed technical coefficients, the RAS ${ }^{11}$ technique is commonly used for updating technical coefficients and transactions based on specified changes to total gross outputs, total interindustry sales, and total interindustry purchases (Miller and Blair 2009). Material efficiency strategies could be represented as changes in technical coefficients or transactions and their effects estimated using RAS, as shown in the Appendix. ${ }^{12}$

\subsection{Material Energy Identity}

The material energy identity is used to conceptually identify and organize energy and material efficiency strategies that are then implemented and analyzed in the IO model. The total energy use of a product system $\left(E_{T}\right)$ can be expressed as the sum of the energy use of its individual stages, $E_{i}$, which include $n$ stages of natural resource extraction, material processing, product manufacture, product use, product end of life, and transportation.

$$
E_{T}=\sum_{i}^{n} E_{i}
$$

The most significant energy use for a given product is typically associated with raw material extraction and material production $\left(E_{m}\right)$ and product use $\left(E_{u}\right)$. For material and energy efficiency analysis the focus is material production total energy. Following Allwood et al. (2011), total energy for the production of a particular material can be expressed as

$$
E_{m}=D \times \frac{M_{p}}{D} \times \frac{M_{S}}{M_{P}} \times \frac{E_{m}}{M_{s}}
$$

where $D$ is final product demand, $M_{p}$ is the total mass of material in the final product, $M_{s}$ is the total mass of material supplied, and $\frac{E_{m}}{M_{S}}$ is the average energy intensity of material production.

This identity can be expanded for greater detail by splitting product demand into new demand $(N)$ and stock replacement demand (stock $S$ and average product lifetime $L$ ) and introducing factors for the fraction of primary, recycled, and reused material $\left(f_{o}, f_{r} \text {, and } f_{u}\right)^{13}$ and their

associated energy intensities $\left(\frac{E_{o}}{M_{o}}, \frac{E_{r}}{M_{r}}\right.$, and $\left.\frac{E_{u}}{M_{u}}\right)$ (Allwood et al. 2011). The material energy identity in this form is steady state. The stock and average lifetime parameters are introduced to enable capturing the effects of changes to product lifetime.

$$
E_{m}=\left(N+\frac{S}{L}\right) \times \frac{M_{p}}{D} \times \frac{M_{s}}{M_{p}} \times\left(f_{o} \frac{E_{o}}{M_{o}}+f_{r} \frac{E_{r}}{M_{r}}+f_{u} \frac{E_{u}}{M_{u}}\right)
$$

\footnotetext{
${ }^{11}$ RAS refers to the variable names of the matrices used by the technique, where " $\mathbf{R}$ is seen to refer to a diagonal matrix of elements modifying rows, the $\mathbf{A}$ to the coefficient matrix being modified, and the $\mathbf{S}$ to the diagonal matrix of column modifiers” (Miller and Blair 2009, 318).

12 RAS is commonly used, but other rebalancing techniques exist. See Lahr and De Mesnard (2004) for a discussion of alternatives.

13 The factors $f_{o}, f_{r}$, and $f_{u}$ are equivalent to $\frac{M_{O}}{M_{S}}, \frac{M_{r}}{M_{S}}$, and $\frac{M_{u}}{M_{S}}$ respectively; they sum to unity.
} 
The resulting expanded material energy identity serves as the foundation for identifying and analyzing potential energy reduction strategies. The material energy identity could be expanded to meet additional analysis needs (e.g., distinguishing between domestic and imported material production) or presented in a log-linearized form to explore parameter sensitivity. Table 1 summarizes categories of energy efficiency and material efficiency strategies and their associated parameters as identified by Allwood et al. (2011). Energy efficiency and material efficiency categories are distinguished by their effect on total material production and absolute energy use (or emissions). Strategies categorized as “energy efficiency” reduce the energy (or emissions) intensity of material production, but they do not necessarily reduce absolute energy use (or emissions) of materials production. Conversely, strategies categorized as "material efficiency" can reduce total material demand and yield reductions in absolute energy use (or emissions) ${ }^{14}$.

Table 1. Summary of Energy Efficiency and Material Efficiency Strategy Categories

\begin{tabular}{lll}
\hline & Strategy Category & Parameters \\
\hline \multirow{2}{*}{ Mnergy } & Energy efficiency & $E_{o}, E_{r}$ \\
& Recycling rate & $f_{r}, f_{o}$ \\
\hline \multirow{2}{*}{ Materials } & Material yield ratio & $M_{s} / M_{p}$ \\
& Longer-lasting products & $L$ \\
& Component reuse & $f_{u}$ \\
& Modularization and remanufacturing & $N$ \\
& Designing products with less material & $M_{p}$ \\
& Material substitution & $E_{m}$ \\
\hline
\end{tabular}

\subsection{Advantages and Limitations of Analysis Framework}

By defining energy flows from primary and secondary energy sectors (e.g., crude oil as the primary energy sector and refined petroleum as the secondary-energy carrier — sector), the hybrid model can satisfy energy conservation conditions that are not necessarily met when using the earlier method of estimating embodied energy use (Miller and Blair 2009). Analyzing historical energy use and projecting future use based on goods and services consumption complements a technology-based approach. The nature of the proposed framework may reveal opportunities for efficiency and novel technologies (e.g., material separation and recovery technologies, remanufacturing and refurbishment technologies, and enabling technologies for minimizing life cycle energy use during product design) that are not apparent with traditional energy efficiency analysis.

Material flow data are likely more difficult to obtain at the level of disaggregation that matches the BEA's detailed IO tables. Existing examples of materials hybrid IO models are based on commodity data from the U.S. Geological Survey and assumptions of material prices (e.g.,

\footnotetext{
14 Material efficiency strategies that reduce prices for materials and products may induce new demand and an associated energy rebound effect, although their intent is an absolute reduction in energy.
} 
dollars per unit weight) (Hawkins et al. 2007). Additional data sources are required for materials other than nonmetallic minerals and metals.

The static nature of traditional IO models and their assumption of fixed technical coefficients makes them appropriate for analyzing marginal changes to total demand, but much less suitable for analyzing potential impacts of new technologies and products, or large changes in demand. The proposed dynamic hybrid IO overcomes these limitations with its ability to represent the implementation of material efficiency strategies with updated technical coefficients and transactions. 


\section{Analyzing Material and Energy Efficiency Strategies-an Example Application}

Material and energy efficiency analysis begins by identifying values for the parameters in Table 1 (page 14) and applying them to the dynamic hybrid IO model to estimate associated changes to material and energy use. This section describes the application of the method to the production of aluminum and plastic beverage containers. This simple example of the type of analysis that can be performed was purposefully chosen to clearly demonstrate the concept of using an IO model as the foundation of material efficiency analysis. The calculations would not be as straightforward in more complex applications, including long-lived capital equipment and infrastructure. It should be noted that several key characteristics of the proposed analytical framework (e.g. a hybrid IO model, dynamic IO adjustments, and identification of net international trade) are not applied in the example. Product use and end-of-life activities are also excluded.

Before exploring the example, it is important to note the distinction between the IO concepts of direct, indirect, and total requirements. The direct requirements IO table provides the "recipe" for producing one monetary unit of industry product. This recipe is depicted as the dollar amount of inputs used directly by that industry to produce its output. The complement to the direct requirements table is the total requirements table, which provides information on direct inputs to production and indirect inputs used in the supply chains of supporting industries. For example, the total requirements for an industry that directly uses natural gas would include the inputs that are used to produce natural gas, the inputs used to produce those inputs, and so on. For more information on the direct and total requirements tables, including their mathematical derivation, see Miller and Blair (2009) and BEA (2009).

In the example explored here, the material and energy efficiency analysis begins with estimating the U.S. economy's baseline demand for beverage containers and the associated material and energy requirements. The production of these commodities is a function of demand for their use in final goods and services. The connection between industrial production and consumers is made by linking IO data to detailed commodity personal consumption expenditure (PCE) ${ }^{15}$ data through a "bridge" developed by the BEA. Beverage container demand can be approximated by the PCE end-use product categories of "coffee, tea, and other beverage materials," "mineral waters, soft drinks, and vegetable juices," and "food furnished to employees (including military).” In 2007, consumer demand for these categories was $\$ 58.419$ billion. This end-use demand is linked to industry transactions data in the IO model by the PCE bridge, which identifies the commodities associated with each PCE end-use product category. The PCE bridge identifies the relevant commodity categories of "soft drink and ice manufacturing” and "scrap," as shown in Table 2. Together these categories account for $\$ 36.755$ billion of the $\$ 58.419$ billion

\footnotetext{
${ }^{15}$ Personal consumption expenditure (PCE) is a measure of household spending on goods and services. PCE is a component of gross domestic product and is computed by the BEA.
} 
for PCE categories of "coffee, tea, and other beverage materials," "mineral waters, soft drinks, and vegetable juices," and "food furnished to employees (including military)." 16

Table 2. Personal Consumption Expenditures (PCE) Bridge, 2007

\begin{tabular}{llc}
\hline PCE Category & Commodity Description & Producers' \\
Value (\$ billion)
\end{tabular}

a Scrap is shown as a negative value because "scrap sold by final users is not part of the gross output of the economy, but it is part of the supply of goods available" (Bureau of Economic Analysis 2009, p. 98).

Table 3 (next page) summarizes the materials (aluminum and plastics) and energy (electricity and natural gas) for soft drink and ice manufacturing. These direct requirements indicate, for example, that input of $\$ 0.12$ of "plastics bottle manufacturing” is used for every $\$ 1.00$ of output from "soft drink and ice manufacturing." Likewise, $\$ 0.0048$ of "natural gas distribution” is used for every $\$ 1.00$ of output from "soft drink and ice manufacturing." It should be noted that with the application of a hybrid IO model, inputs of materials would be shown in mass units (e.g. pounds), inputs of energy would be shown in physical energy units (e.g., Btu), and all other inputs, such as advertising services and insurance services would be shown in dollar units.

The amount of materials and energy purchased directly by production of "soft drink and ice manufacturing” is estimated by multiplying the industry’s total output (i.e., the sum of PCE, intermediate demand from other industries, inventory changes, and net exports) by the appropriate direct requirements coefficient. Using this calculation, the $\$ 42.419$ billion total output — which includes the PCE value of $\$ 39.189$ billion plus use as an intermediate good for other industries, net imports, inventory changes - requires $\$ 5.61$ billion of plastics (bottles and other plastics) and $\$ 0.203$ billion of energy (natural gas).

\footnotetext{
16 The other commodities associated with the remaining \$21.664 billion of these PCE categories are not considered relevant to the example material efficiency analysis. They include "coffee and tea manufacturing," "flavoring syrup and concentrate manufacturing,” and "frozen food manufacturing.”
} 
Table 3. Energy and Material Direct Requirements for "Soft Drink and Ice Manufacturing," 2007 (\$/\$)

\begin{tabular}{lll}
\hline & Commodity Description & $\begin{array}{c}\text { Soft Drink and Ice } \\
\text { Manufacturing (\$\$) }\end{array}$ \\
\hline $\begin{array}{l}\text { Materials } \\
\begin{array}{l}\text { (aluminum and } \\
\text { plastics) }\end{array}\end{array}$ & $\begin{array}{l}\text { Aluminum product manufacturing from } \\
\text { purchased aluminum }\end{array}$ & 0.10 \\
& $\begin{array}{l}\text { Metal can, box, and other metal container } \\
\text { (light gauge) manufacturing }\end{array}$ & 0.011 \\
& $\begin{array}{l}\text { Plastics bottle manufacturing } \\
\text { Other plastics product manufacturing }\end{array}$ & 0.12 \\
& $\begin{array}{l}\text { Electric power generation, transmission, } \\
\text { and distribution }\end{array}$ & 0.015 \\
\hline and natural gas) & Natural gas distribution & 0.0056 \\
\hline All other commodities & & 0.0048 \\
\hline
\end{tabular}

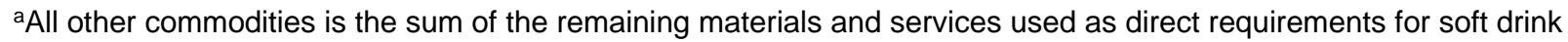
and ice manufacturing. The largest direct requirement is flavoring syrup and concentrate manufacturing, which represents nearly $17 \%$ of direct requirements.

The direct requirements table provides only materials and energy that are purchased by soft drink and ice manufacturers. To estimate the total amount of materials and energy required in the economy to produce $\$ 1.00$ of "soft drink and ice manufacturing” output, the total requirements table is used. The total requirements table can be thought of as the compilation of direct requirements for the entire supply chain of a certain product, in addition to the inputs used directly in producing the product. The total requirements equivalent to Table 3 is shown as Table 4. Examination of the coefficients for electricity and natural gas included in Table 4 highlight the differences between total requirements and direct requirements. By including the indirect requirements of suppliers and suppliers' suppliers and so on, electricity and natural gas requirements increase by $426 \%$ and $387 \%$ respectively. 
Table 4. Energy and Material Total Requirements for Soft Drink and Ice Manufacturing, 2007 (\$/\$)

\begin{tabular}{llc}
\hline & Commodity Description & $\begin{array}{c}\text { Soft Drink and Ice } \\
\text { Manufacturing }(\$ / \$)\end{array}$ \\
\hline $\begin{array}{l}\text { Materials } \\
\text { (aluminum and } \\
\text { plastics) }\end{array}$ & $\begin{array}{l}\text { Aluminum product manufacturing from } \\
\text { purchased aluminum } \\
\text { Metal can, box, and other metal } \\
\text { container (light gauge) manufacturing } \\
\text { Plastics bottle manufacturing }\end{array}$ & 0.12 \\
& Other plastics product manufacturing & 0.016 \\
\hline $\begin{array}{l}\text { Energy } \\
\text { (electricity and } \\
\text { natural gas) }\end{array}$ & $\begin{array}{l}\text { Electric power generation, transmission, } \\
\text { and distribution }\end{array}$ & 0.12 \\
\hline All other commodities & 0.029 \\
\hline
\end{tabular}

aAll other commodities is the sum of the remaining materials and services used as total requirements for soft drink and ice manufacturing. Unlike the direct requirements shown in Table 3, this value includes the value of output of the soft drink and ice manufacturing industry itself. Like Table 3, however, the largest requirement is flavoring syrup and concentrate manufacturing

Table 4 shows only the selected few input categories available for "soft drink and ice manufacturing.” The complete total requirements table includes the use of many other inputssuch as mining of mineral ore for aluminum production and the extraction of oil and gas for plastic resin production - that do not appear in the direct requirements table. This is consistent with the fact that soft drink and ice manufacturers do not buy these raw materials directly. As with the direct requirements calculation, the total amount of materials and energy required in the economy to produce $\$ 1.00$ of "soft drink and ice manufacturing" output is estimated by multiplying the industry's total output by the appropriate total requirements coefficient. Using this calculation, the $\$ 42.419$ billion total output requires $\$ 5.86$ billion of plastic (bottles and other plastics) and nearly $\$ 1$ billion of natural gas. Table 5 summarizes the total and direct requirements. 
Table 5. Direct and Total Requirements for End-Use Product Demand Associated with "Soft Drink and Ice Manufacturing"

\begin{tabular}{|c|c|c|c|c|c|}
\hline & Commodity Description & $\begin{array}{l}\text { Direct } \\
\text { Requirements } \\
(\$ / \$)\end{array}$ & $\begin{array}{l}\text { Direct } \\
\text { Demand }(\$ B)\end{array}$ & $\begin{array}{l}\text { Total } \\
\text { Requirements } \\
(\$ / \$)\end{array}$ & $\begin{array}{l}\text { Total } \\
\text { Demand } \\
(\$ \mathrm{~B})\end{array}$ \\
\hline \multirow{4}{*}{$\begin{array}{l}\text { Materials } \\
\text { (aluminum and } \\
\text { plastics) }\end{array}$} & $\begin{array}{l}\text { Aluminum product manufacturing from } \\
\text { purchased aluminum }\end{array}$ & 0.10 & 4.38 & 0.12 & 5.13 \\
\hline & $\begin{array}{l}\text { Metal can, box, and other metal container (light } \\
\text { gauge) manufacturing }\end{array}$ & 0.011 & 0.471 & 0.016 & 0.665 \\
\hline & Plastics bottle manufacturing & 0.12 & 4.97 & 0.12 & 5.04 \\
\hline & Other plastics product manufacturing & 0.015 & 0.640 & 0.019 & 0.82 \\
\hline \multirow{2}{*}{$\begin{array}{l}\text { Energy } \\
\text { (electricity and } \\
\text { natural gas) }\end{array}$} & $\begin{array}{l}\text { Electric power generation, transmission, and } \\
\text { distribution }\end{array}$ & 0.0056 & 0.237 & 0.029 & 1.25 \\
\hline & Natural gas distribution & 0.0048 & 0.203 & 0.023 & 0.989 \\
\hline \multicolumn{2}{|c|}{ All other commodities } & 0.74 & 31.5 & 2.51 & 106 \\
\hline
\end{tabular}


The material energy identity serves as the blueprint for identifying and implementing material and energy efficiency strategies. Table 6 provides notional values that could be used for analysis of different material and energy efficiency strategies for aluminum and plastic beverage containers. For example, the $12 \%$ potential decrease in energy intensity for plastic production would be implemented by adjusting the technical coefficients for natural gas and electricity in the direct requirements table for plastic resin manufacturing. Similarly, the material efficiency strategy of lightweighting aluminum beverage containers would be implemented by reducing the direct requirements of aluminum in the "soft drink and ice manufacturing” industry by $2 \%$.

Table 6. Material and Energy Efficiency Potential Analysis: Notional Values

\begin{tabular}{l|cc}
\hline \multirow{2}{*}{ Strategy (Parameter) } & Beverage Containers (potential increase/decrease) \\
\cline { 2 - 3 } Energy Efficiency & Aluminum & Plastic \\
Energy intensity: primary production $\left(E_{o} / M_{o}\right)$ & $-27 \%$ & $-12 \%$ \\
Energy intensity: secondary production $\left(E_{r} / M_{r}\right)$ & $-2 \%$ & $-5 \%$ \\
Recycling rate $\left(\mathrm{f}_{\mathrm{r}}\right)$ & $+10 \%$ & $+25 \%$ \\
Recycling rate $\left(\mathrm{f}_{\mathrm{o}}\right)$ & $+20 \%$ & $+45 \%$ \\
\hline Material Efficiency & & \\
Material yield ratio $\left(\mathrm{M}_{\mathrm{s}} / \mathrm{M}_{\mathrm{p}}\right)$ & $+15 \%$ & $+7 \%$ \\
Product lifetime $(\mathrm{L})$ & $\mathrm{N} / \mathrm{A}$ & $\mathrm{N} / \mathrm{A}$ \\
Component reuse $\left(\mathrm{f}_{\mathrm{u}}\right)$ & $\mathrm{N} / \mathrm{A}$ & $\mathrm{N} / \mathrm{A}$ \\
Remanufacturing $(\mathrm{N})$ & $\mathrm{N} / \mathrm{A}$ & $\mathrm{N} / \mathrm{A}$ \\
Less material $\left(\mathrm{M}_{\mathrm{p}}\right)$ & $-2 \%$ & $-5 \%$ \\
Material substitution $\left(\mathrm{E}_{\mathrm{m}}\right)$ & $\mathrm{N} / \mathrm{A}$ & $\mathrm{N} / \mathrm{A}$ \\
\hline
\end{tabular}

Estimating the potential material and energy impacts in either case requires dynamic IO analysis, as proposed in the analysis framework, because both involve changes to technical coefficients in the direct requirements table. However, potential impacts of changes to final demand for "soft drink and ice manufacturing" can be analyzed using the total requirements values shown in Table 5. For example, reducing total output by $10 \%$ would reduce plastic bottle production by $\$ 0.504$ billion and natural gas consumption by $\$ 0.0989$ billion. 


\section{Summary}

Existing energy efficiency analysis and programs, including associated technology research and development and deployment activities supported by DOE focus on energy at the point of use in buildings, industrial processes, and transportation. Efforts to address the energy embodied in materials through strategies and technologies that reduce raw material production-while maintaining the highest-value function and use of materials-offer a complementary and expansive approach to traditional energy efficiency analysis. However, the DOE energy analysis community currently lacks analytical tools that are appropriate for (1) estimating on an industry and economy-wide basis energy efficiency potential achieved through material efficiency strategies and (2) evaluating how these new strategies may complement existing energy efficiency efforts. Overlooking the opportunities presented by material efficiency strategies may miss an energy reduction potential equivalent to the magnitude of traditionally defined energy efficiency (Cooper et al. 2017). Additionally, energy efficiency alone has been shown to be insufficient for meeting emissions reduction targets for materials production given anticipated future materials demand (Milford et al. 2013).

This report describes a standardized analysis framework that would enable calculation of embodied and direct energy as well as estimation of energy reduction potential achieved through changes in material use. The proposed framework meets this functionality by spanning the entire U.S. economy, including international trade flows; capturing material and energy use in products and services from raw material extraction to disposal; maintaining material and energy balances; and adjusting dynamically to absolute and relative changes in materials and energy use.

The proposed analytical framework is composed of two main elements: a dynamic hybrid IO model and a material energy identity. The dynamic hybrid IO model depicts the material, energy, and financial commodity flows between industries that define the structure of the U.S. economy. The model is used to estimate the potential effects of individual or combined energy and material efficiency strategies. The material energy identity acts as a way of identifying and parameterizing energy and material efficiency strategies, which are then implemented and analyzed in the dynamic hybrid IO model.

A simple example of applying the proposed framework was chosen purposely to illustrate the concept of reducing energy use through changes to material efficiency, as well as to demonstrate IO analysis. The goals of this report are to establish the importance of considering the energy embodied in materials and to propose an analytical framework that can estimate the energy reduction potential of material efficiency strategies. Much more detailed and analytically satisfying examples could be developed by implementing the proposed framework.

The proposed material and energy efficiency analysis framework would provide a tool to identify and assess the energy reduction potential of material efficiency strategies and technologies. The strategies that emerge from this type of analysis, including remanufacturing and extending product lifetimes have not typically been a focus of traditional efficiency programs, and they represent unexplored opportunities to reduce the use of energy and other resources and to reduce pollutant emissions. 


\section{References}

Allwood, Julian M., Michael F. Ashby, Timothy G. Gutowski, and Ernst Worrell. 2011. “Material Efficiency: A White Paper.” Resources, Conservation and Recycling 55 (3): 362-81. https://doi.org/10.1016/j.resconrec.2010.11.002.

—. 2013. "Material Efficiency: Providing Material Services with Less Material Production.” Philosophical Transactions of the Royal Society of London A: Mathematical, Physical and Engineering Sciences 371 (1986): 20120496.

https://doi.org/10.1098/rsta.2012.0496.

Allwood, Julian M., Jonathan M. Cullen, and Rachel L. Milford. 2010. “Options for Achieving a 50\% Cut in Industrial Carbon Emissions by 2050.” Environmental Science \& Technology 44 (6): 1888-94. https://doi.org/10.1021/es902909k.

Argonne National Laboratory. 2017. “The Greenhouse Gases, Regulated Emissions, and Energy Use in Transportation (GREET) Model.” GREET® Model. 2017. https:/greet.es.anl.gov/.

BIO Intelligence Service. 2014. "Development of Guidance on Extended Producer Responsibility (EPR).” European Commission - DG Environment. http://ec.europa.eu/environment/waste/pdf/target_review/Guidance\%20on\%20EPR\%20\%20Final\%20Report.pdf.

Bocken, Nancy M. P., Ingrid de Pauw, Conny Bakker, and Bram van der Grinten. 2016. "Product Design and Business Model Strategies for a Circular Economy.” Journal of Industrial and Production Engineering 33 (5): 308-20. https://doi.org/10.1080/21681015.2016.1172124.

Bureau of Economic Analysis. 2009. "Concepts and Methods of the U.S. Input-Output Accounts.” Washington, D.C.: U.S. Department of Commerce. https://www.bea.gov/papers/pdf/IOmanual_092906.pdf.

Central Committee of the Communist Party of China. 2016. "The 13th Five-Year Plan For Economic and Social Development of the People's Republic of China (2016-2020).” Beijing, China. http://en.ndrc.gov.cn/newsrelease/201612/P020161207645765233498.pdf.

Choate, William T., and John A.S. Green. 2003. "U.S. Aluminum Production Energy Requirements: Historical Perspective, Theoretical Limits, and New Opportunities.” In Sustainability and Industry: Increasing Energy Efficiency \& Reducing Emissions. ACEEE. http://aceee.org/files/proceedings/2003/data/papers/SS03_Panel1_Paper02.pdf.

Cooper, Samuel J. G., Jannik Giesekam, Geoffrey P. Hammond, Jonathan B. Norman, Anne Owen, John G. Rogers, and Kate Scott. 2017. “Thermodynamic Insights and Assessment of the 'Circular Economy.”’' Journal of Cleaner Production 162 (Supplement C): 1356-67. https://doi.org/10.1016/j.jclepro.2017.06.169. 
Cooper, Simone, Alexandra C. H. Skelton, Anne Owen, Danielle Densley-Tingley, and Julian M. Allwood. 2016. "A Multi-Method Approach for Analysing the Potential Employment Impacts of Material Efficiency.” Resources, Conservation and Recycling 109 (May): 54-66. https://doi.org/10.1016/j.resconrec.2015.11.014.

Davis, Steven J., and Ken Caldeira. 2010. "Consumption-Based Accounting of CO2 Emissions.” Proceedings of the National Academy of Sciences 107 (12): 5687-92. https://doi.org/10.1073/pnas.0906974107.

Directive 2005/32/EC of the European Parliament and of the Council of 6 July 2005 Establishing a Framework for the Setting of Ecodesign Requirements for Energy-Using Products and Amending Council Directive 92/42/EEC and Directives 96/57/EC and 2000/55/EC of the European Parliament and of the Council. 2005. http://eur-lex.europa.eu/legalcontent/EN/ALL/?uri=CELEX\%3A32005L0032.

“Dynamix | Decoupling Growth from Resource Use and Its Environmental Impacts.” n.d. Accessed September 28, 2016. http://dynamix-project.eu/.

EIA. 2009. “The National Energy Modeling System: An Overview 2009.” EIA. https://www.eia.gov/outlooks/aeo/nems/overview/pdf/0581(2009).pdf.

Energy Information Administration. 2017. “Data.” Consumption and Efficiency. 2017. https://www.eia.gov/consumption/data.php.

EPA. 2016. "G7 Alliance on Resource Efficiency: U.S.-Hosted Workshop on the Use of Life Cycle Concepts in Supply Chain Management to Achieve Resource Efficiency.” US EPA. 2016. https://www.epa.gov/smm/g7-alliance-resource-efficiency-us-hosted-workshop-use-life-cycleconcepts-supply-chain.

EPA Office of Land and Emergency Management. 2016. “Advancing Resource Efficiency in the Supply Chain-Observations and Opportunities for Action.” EPA 530-R-16-014. Washington, D.C.: U.S. Environmental Protection Agency. https://www.epa.gov/sites/production/files/201609/documents/g7_us_workshop_opportunities_report_final_091416_508compliant_v3__copy.pdf.

EPRI. 2017. “State Level Electric Energy Efficiency Potential Estimates.” Palo Alto, CA: Electric Power Research Institute (EPRI). https://www.energy.gov/sites/prod/files/2017/05/f34/epri_state_level_electric_energy_efficiency _potential_estimates_0.pdf.

Ernst Worrell, Mark Levine, Lynn Price, Nathan Martin, Richard van den Broek, and Kornelis Block. 1997. "Potentials and Policy Implications of Energy and Material Efficiency Improvement.” New York: United Nations. http://escholarship.org/uc/item/4p49t9z8.

European Commission. 2011. “Roadmap to a Resource Efficient Europe.” COM(2011) 571. Brussels: European Commission. http://www.efr2.org/html/downloads/COM_Resourceefficient_Europe_Flagship_Initiative_under_EU_2020_COM_2011_21_Final2-en.pdf. 
- 2015a. "Closing the Loop- An EU Action Plan for the Circular Economy. Annex I." COM(2015) 614 final. Brussels: European Commission. http://eurlex.europa.eu/resource.html?uri=cellar:8a8ef5e8-99a0-11e5-b3b701aa75ed71a1.0012.02/DOC_2\&format=PDF.

614. Brussels: European Commission. http://eurlex.europa.eu/resource.html?uri=cellar:8a8ef5e8-99a0-11e5-b3b7-

01aa75ed71a1.0012.02/DOC_1\&format=PDF.

European Environment Agency. 2016. "More from Less — Material Resource Efficiency in Europe.” Publication EEA Report No 10/2016. Luxembourg: European Environment Agency. https://www.eea.europa.eu/publications/more-from-less.

Eurpoean Commission. 2017. "Raw Materials Information System.” 2017. http://rmis.jrc.ec.europa.eu/.

Ewing, Brad R., Troy R. Hawkins, Thomas O. Wiedmann, Alessandro Galli, A. Ertug Ercin, Jan Weinzettel, and Kjartan Steen-Olsen. 2012. "Integrating Ecological and Water Footprint Accounting in a Multi-Regional Input-output Framework.” Ecological Indicators 23 (Supplement C): 1-8. https://doi.org/10.1016/j.ecolind.2012.02.025.

Federal Ministry for the Environment, Nature Conservation, Building and Nuclear Safety. 2012. “German Resource Efficiency Programme (ProgRess).” Berlin: Federal Ministry for the Environment, Nature Conservation, Building and Nuclear Safety. http://www.bmub.bund.de/fileadmin/Daten_BMU/Pools/Broschueren/progress_broschuere_en_b f.pdf.

Gilbert, P., P. Wilson, C. Walsh, and P. Hodgson. 2017. "The Role of Material Efficiency to Reduce CO2 Emissions during Ship Manufacture: A Life Cycle Approach.” Marine Policy 75: 227-37. https://doi.org/http://www.sciencedirect.com/science/article/pii/S0308597X1630077X?via\%3Di hub.

Gutowski, T. G. 2014. "Materials Production; Energy Used and Carbon Emitted.” http://web.mit.edu/2.813/www/ClassSlides2014/MaterialsProduction2014.pdf.

Hanes, Rebecca J., and Alberta Carpenter. 2017. "Evaluating Opportunities to Improve Material and Energy Impacts in Commodity Supply Chains.” Environment Systems and Decisions 37 (1): 6-12. https://doi.org/10.1007/s10669-016-9622-5.

Herendeen, Robert, and Jerry Tanaka. 1976. “Energy Cost of Living.” Energy 1 (2): 165-78. https://doi.org/10.1016/0360-5442(76)90015-3.

Hoekstra, Rutger, and Jeroen C. J. M. van den Bergh. 2006. "Constructing Physical Input-output Tables for Environmental Modeling and Accounting: Framework and Illustrations.” Ecological Economics 59 (3): 375-93. https://doi.org/10.1016/j.ecolecon.2005.11.005. 
Holmes, C., and S. Mullen-Trento. 2017. "State Level Electric Energy Efficiency Potential Estimates.” 3002009988. Palo Alto, CA: Electric Power Research Institute (EPRI).

https://energy.gov/sites/prod/files/2017/05/f34/epri_state_level_electric_energy_efficiency_pote ntial_estimates_0.pdf.

John A. Laitner, Steven Nadel, R. Neil Elliott, Harvey Sachs, and A. Siddiq Khan. 2012. "The Long-Term Energy Efficiency Potential: What the Evidence Suggests.” E121. Washington, D.C.: American Council for an Energy-Efficient Economy. http://aceee.org/research-report/E121.

Lahr, Michael, and Louis De Mesnard. 2004. "Biproportional Techniques in Input-Output Analysis: Table Updating and Structural Analysis.” Economic Systems Research 16 (2): 115134.

Lenzen, Manfred, Keiichiro Kanemoto, Daniel Moran, and Arne Geschke. 2012. "Mapping the Structure of the World Economy.” Environmental Science \& Technology 46 (15): 8374-81. https://doi.org/10.1021/es300171x.

Lenzen, Manfred, Daniel Moran, Keiichiro Kanemoto, and Arne Geschke. 2013. "Building Eora: A Global Multi-Region Input-Output Database at High Country and Sector Resolution.” Economic Systems Research 25 (1): 20-49. https://doi.org/10.1080/09535314.2013.769938.

Leontief, Wassily W. 1936. "Quantitative Input and Output Relations in the Economic Systems of the United States.” The Review of Economics and Statistics 18 (3): 105-25.

https://doi.org/10.2307/1927837.

Ma, Linwei, Julian M. Allwood, Jonathan M. Cullen, and Zheng Li. 2012. "The Use of Energy in China: Tracing the Flow of Energy from Primary Source to Demand Drivers.” Energy 40 (1): 174-88. https://doi.org/10.1016/j.energy.2012.02.013.

Margolis, Jason. 2017. "Sweden Tries to Curb Buy-and-Throw-Away Culture through Tax Breaks.” PRI’s The World. Public Radio International. https://www.pri.org/stories/2017-0102/sweden-tries-curb-buy-and-throw-away-culture-through-tax-breaks.

Mathews, John A., and Hao Tan. 2016. “Circular Economy: Lessons from China.” Nature News 531 (7595): 440. https://doi.org/10.1038/531440a.

Milford, Rachel L., Julian M. Allwood, and Jonathan M. Cullen. 2011. “Assessing the Potential of Yield Improvements, through Process Scrap Reduction, for Energy and CO 2 Abatement in the Steel and Aluminium Sectors.” Resources, Conservation and Recycling 55 (12): 1185-1195.

Milford, Rachel L., Stefan Pauliuk, Julian M. Allwood, and Daniel B. Müller. 2013. “The Roles of Energy and Material Efficiency in Meeting Steel Industry CO2 Targets.” Environmental Science \& Technology 47 (7): 3455-62. https://doi.org/10.1021/es3031424.

Miller, Ronald E., and Peter D. Blair. 2009. Input-Output Analysis: Foundations and Extensions. Cambridge University Press.

https://books.google.com/books?hl=en\&lr=\&id=viHaAgAAQBAJ\&oi=fnd\&pg=PR24\&dq=Inpu t-output+analysis\&ots=gpEpcxfV6W\&sig=skZ4DoHmM_qoq4CK-aivCyQSxEI. 
Ming, X. U. 2010. "Development of the Physical Input Monetary Output Model for Understanding Material Flows within Ecological-Economic Systems.” Journal of Resources and Ecology 1 (2): 123-134.

National People's Congress Standing Committee. 2013. “Circular Economy Promotion Law of the People’s Republic of China.” Congressional-Executive Commission on China. February 14, 2013. https://www.cecc.gov/resources/legal-provisions/circular-economy-promotion-law-of-thepeoples-republic-of-china-chinese.

National Renewable Energy Laboratory. 2017. "Materials Flows through Industry Tool.” Advanced Manufacturing Research. 2017. https://www.nrel.gov/manufacturing/mfi-modelingtool.html.

—. n.d. “Buildings Industry Transportation Electricity Scenarios.” BITES Tool -- Beta. Accessed November 16, 2017. https://bites.nrel.gov/about.php.

“Nike Aims to Transform Manufacturing.” 2016. Nike News. 2016. http://about.nike.com/pages/transform-manufacturing.

Prakash, Siddharth, Ran Liu, Karsten Schischke, and Lutz Stobbe. 2012. “Timely Replacement of a Notebook under Consideration of Environmental Aspects.” Federal Environment Agency. http://www.umweltbundesamt.de/sites/default/files/medien/461/publikationen/4317.pdf.

“Recycled Materials: Sustainability Report 2015/16: Ford Motor Company.” 2016. 2016. http://corporate.ford.com/microsites/sustainability-report-2015-16/products-greener-materialsrecycled.html.

Singh, Shweta, Jana E. Compton, Troy R. Hawkins, Daniel J. Sobota, and Ellen J. Cooter. 2017. “A Nitrogen Physical Input-Output Table (PIOT) Model for Illinois.” Ecological Modelling 360 (Supplement C): 194-203. https://doi.org/10.1016/j.ecolmodel.2017.06.015.

Söderholm, Patrik, and John E. Tilton. 2012a. "Material Efficiency: An Economic Perspective.” Resources, Conservation and Recycling 61 (April): 75-82. https://doi.org/10.1016/j.resconrec.2012.01.003.

_. 2012b. "Material Efficiency: An Economic Perspective.” Resources, Conservation and Recycling 61 (Supplement C): 75-82. https://doi.org/10.1016/j.resconrec.2012.01.003.

Sustainable Manufacturing Innovation Alliance. 2017. “The REMADE Institute.” The REMADE Institute. 2017. https://remadeinstitute.org/.

Thomas Wiedmann. 2009. “A Review of Recent Multi-Region Input-output Models Used for Consumption-Based Emission and Resource Accounting.” Ecological Economics, Special Section: Analyzing the global human appropriation of net primary production - processes, trajectories, implications, 69 (2): 211-22. https://doi.org/10.1016/j.ecolecon.2009.08.026. 
Treloar, Graham J. 1997. “Extracting Embodied Energy Paths from Input-output Tables: Towards an Input-output-Based Hybrid Energy Analysis Method.” Economic Systems Research 9 (4): 375-391.

U.S. Department of Energy. 2010. “Environmental Assessment for 10 CFR Part 431 Energy Conservation Standards: Energy Conservation Standards for Residential Water Heaters, Direct Heating Equipment, and Pool Heaters.” https:/energy.gov/sites/prod/files/nepapub/nepa_documents/RedDont/EA-1774-FEA-2010.pdf.

—. 2016. “Industrial Energy Efficiency Potential Analysis.” Washington, D.C.: U.S. Department of Energy. https://www.energy.gov/sites/prod/files/2017/04/f34/energy-savings-bystate-industrial-methodology.pdf.

. 2017a. “Appliance and Equipment Standards Program.” 2017. https://energy.gov/eere/buildings/appliance-and-equipment-standards-program.

—. 2017b. “Energy Efficiency Potential Studies Catalog.” Energy Efficiency Potential Studies Catalog. 2017. https://www.energy.gov/eere/slsc/energy-efficiency-potential-studiescatalog.

U.S. Department of Energy Advanced Manufacturing Office. 2016. “Advanced Manufacturing Office (AMO) Multi-Year Program Plan For Fiscal Years 2017 Through 2021.” Washington, D.C.: U.S. Department of Energy Office of Energy Efficiency and Renewable Energy. https://energy.gov/eere/amo/downloads/advanced-manufacturing-office-amo-multi-yearprogram-plan-fiscal-years-2017.

U.S. Department of Energy Building Technologies Office. 2017. “Welcome to Scout.” 2017. http://scout-bto.readthedocs.io/en/latest/index.html.

U.S. EPA Office of Research and Development (ORD). 2017. “USEEIO Satellite Files.” June 18, 2017. https://catalog.data.gov/dataset/useeio-satellite-tables.

Vendries Algarin, Jorge, Troy R. Hawkins, Joe Marriott, and Vikas Khanna. 2017. "Effects of Using Heterogeneous Prices on the Allocation of Impacts from Electricity Use: A Mixed-Unit Input-Output Approach.” Journal of Industrial Ecology 21 (5): 1333-1343. https://doi.org/10.1111/jiec.12502.

Walls, Margaret A. 2003. "The Role of Economics in Extender Producer Responsibility: Making Policy Choices and Setting Policy Goals.” Discussion Paper 03-11. Washington, D.C.: Resources for the Future. http://www.rff.org/files/sharepoint/WorkImages/Download/RFF-DP03-11.pdf.

Walz, Rainer. 2011. "Employment and Structural Impacts of Material Efficiency Strategies: Results from Five Case Studies.” Journal of Cleaner Production, Critical Perspectives of Sustainable Development Research and Practice, 19 (8): 805-15. https://doi.org/10.1016/j.jclepro.2010.06.023. 
Wiedmann, Thomas O., Heinz Schandl, Manfred Lenzen, Daniel Moran, Sangwon Suh, James West, and Keiichiro Kanemoto. 2015. "The Material Footprint of Nations.” Proceedings of the National Academy of Sciences 112 (20): 6271-76. https://doi.org/10.1073/pnas.1220362110.

Wiedmann, Thomas O., Heinz Schandl, and Daniel Moran. 2014. “The Footprint of Using Metals: New Metrics of Consumption and Productivity.” Environmental Economics and Policy Studies 17 (3): 369-88. https://doi.org/10.1007/s10018-014-0085-y.

Williams, Robert H., Eric D. Larson, and Marc H. Ross. 1987. "Materials, Affluence, and Industrial Energy Use.” Annual Review of Energy 12 (1): 99-144.

“Worn Wear: Better Than New - Patagonia.Com.” 2016. Better Than New. 2016. http://www.patagonia.com/worn-wear.html.

Worrell, E., A. P. C. Faaij, G. J. M. Phylipsen, and K. Blok. 1995. “An Approach for Analysing the Potential for Material Efficiency Improvement.” Resources, Conservation and Recycling 13 (3-4): 215-32. https://doi.org/10.1016/0921-3449(94)00050-F.

Wortler, Martin, Felix Schuler, Nicole Voigt, Torben Schmidt, Peter Dahlmann, Hans Bodo Lungen, and Jean-Theo Ghenda. 2013. “Steel's Contribution to a Low-Carbon Europe 2050: Technical and Economic Analysis of the Sector's CO2 Abatement Potential.” Boston, MA: Boston Consulting Group. http://www.stahl-online.de//wpcontent/uploads/2013/09/Schlussbericht-Studie-Low-carbon-Europe-2050_-Mai-20131.pdf.

WSP Parsons Brinckerhoff, and DNV-GL. 2015. “Industrial Decarbonisation \& Energy Efficiency Roadmaps to 2050: Iron and Steel.” Pathways to Decarbonisation in 2050. UK Department of Energy \& Climate Change and Department for Business, Innovation \& Skills. https://www.gov.uk/government/uploads/system/uploads/attachment_data/file/416667/Iron_and_ Steel_Report.pdf.

Yang, Yi, Wesley W. Ingwersen, Troy R. Hawkins, Michael Srocka, and David E. Meyer. 2017. "USEEIO: A New and Transparent United States Environmentally-Extended Input-Output Model.” Journal of Cleaner Production 158 (Supplement C): 308-18. https://doi.org/10.1016/j.jclepro.2017.04.150. 


\section{Appendix}

This Appendix summarizes the structure and basic mathematical operations of the proposed dynamic hybrid IO model based on examples provided by Miller and Blair (2009). Please see Ming (2010); Miller and Blair (2009); Bureau of Economic Analysis (2009); Hoekstra and van den Bergh (2006); and Treloar (1997), among others, for additional information and example applications of the concepts summarized here.

\section{A.1 Hybrid IO Model}

Consider a two-sector economy comprised of one industry that produces an energy carrier and one industry that produces a single type of widget for use in the energy and widget industries. Final demand represents use of energy and widgets by consumers. Table A1 summarizes the monetary account of the economy, which provides transactions of energy and widgets measured in monetary (\$) values; Table A2 summarizes the energy account of the economy, which provides the physical values (TBtu) of energy transformed by the economy.

Table A1. Monetary Account (values in \$million)

\begin{tabular}{|c|c|c|c|c|}
\hline & Widgets & Energy & Final Demand & Total Output \\
\hline Widgets & 5 & 30 & 50 & 85 \\
\hline Energy & 10 & 20 & 40 & 70 \\
\hline
\end{tabular}

Table A2. Energy Account (values in TBtu)

\begin{tabular}{|c|c|c|c|c|}
\hline & Widgets & Energy & Final Demand & Total Output \\
\hline Energy & 25 & 40 & 75 & 140 \\
\hline
\end{tabular}

These two tables are then used to construct a direct energy requirements matrix and a total energy requirements matrix. The direct energy requirements matrix defines the first use of energy for industrial production; the total energy requirements matrix defines the sum of direct and indirect (i.e., embodied) use of energy for industrial production.

The traditional IO model accounting identity defines total outputs of an economy as the sum of interindustry transactions and total final demand. This identity in matrix notation is

$$
\mathbf{Z i}+\mathbf{f}=\mathbf{x}
$$

Where $\mathbf{Z}$ is the interindustry transactions matrix, $\mathbf{i}$ is a column vector of 1 's, $\mathbf{f}$ is the total final demand vector, and $\mathbf{x}$ is the total outputs vector. As identified by Miller and Blair (2009), the analogous energy-only accounting identity can be defined as

$$
\mathrm{Ei}+\mathrm{q}=\mathbf{g}
$$

where $\mathbf{E}$ is the matrix of energy flows from energy-producing industries to all other sectors, $\mathbf{i}$ is a column vector of 1's, $\mathbf{q}$ is the vector of energy delivered to final demand, and $\mathbf{g}$ is the total energy use vector. 
Miller and Blair (2009) describe how a hybrid model is created by replacing rows of monetary transactions for energy-producing industries in $\mathbf{Z}$ with the corresponding rows in physical units from the energy flows matrix $\mathbf{E}$. The resulting transactions matrix, $\mathbf{Z}^{*}$, contains energy rows measured in Btu and non-energy rows measured in dollars. The $\mathbf{Z}, \mathbf{E}$, and $\mathbf{Z}^{*}$ matrices based on Table A1 and Table A2 are shown below.

$$
\begin{aligned}
Z & =\left[\begin{array}{cc}
5 & 30 \\
10 & 20
\end{array}\right] \\
E & =\left[\begin{array}{ll}
25 & 40
\end{array}\right] \\
Z^{*} & =\left[\begin{array}{cc}
5 & 30 \\
25 & 40
\end{array}\right]
\end{aligned}
$$

The units of $\mathbf{Z}^{*}$ and the remaining portions of the hybrid model identity, $\mathbf{f}^{*}$ and $\mathbf{x}^{*}$, are shown below.

$$
\begin{gathered}
\mathrm{Z}^{*}=\left[\begin{array}{cc}
\$ & \$ \\
\mathrm{Btu} & \mathrm{Btu}
\end{array}\right] \\
\mathbf{f}^{*}=\left[\begin{array}{c}
\$ \\
\text { Btu }
\end{array}\right] \\
\mathbf{x}^{*}=\left[\begin{array}{c}
\$ \\
\text { Btu }
\end{array}\right]
\end{gathered}
$$

The hybrid model identity can then be used to obtain the direct requirements matrix, $\mathrm{A}^{*}$, whose derivation and units are as follows:

$$
\mathrm{A}^{*}=\mathrm{Z}^{*}(\widehat{\mathbf{x}})^{-1}=\left[\begin{array}{cc}
\$ / \$ & \$ / \text { Btu } \\
\mathrm{Btu} / \$ & \mathrm{Btu} / \mathrm{Btu}
\end{array}\right]
$$

Each element of the hybrid direct requirements matrix is in terms of Btu or dollar requirement per unit of total output. The direct energy requirements calculated from Table A1 and A2 are represented as two row vectors because our example economy is composed of just two sectors. The calculated direct energy requirements are equal to [0.294, 0.285], which are interpreted as a direct requirement of $0.294 \mathrm{MMBtu} / \$$ for total widget output and 0.285 MMBtu/MMBtu for final energy industry output.

The total requirements matrix, $\mathrm{L}^{*}$, shares the same units as the direct requirements matrix and is defined as

$$
\mathbf{L}^{*}=\left(\mathrm{I}-\mathbf{A}^{*}\right)^{-1}=\left[\begin{array}{cc}
\$ / \$ & \$ / \text { Btu } \\
\text { Btu/ } \$ & \text { Btu/Btu }
\end{array}\right]
$$

Each element of the hybrid total requirements matrix is in terms of Btu or dollar requirement per unit of final demand. Like the direct energy requirements, the total energy requirements calculated from Table A1 and A2 are represented as two row vectors. The calculated total energy requirements are equal to [0.482, 1.54], which are interpreted as a direct requirement of 0.482 $\mathrm{MMBtu} / \$$ for final widget demand and 1.54 MMBtu/MMBtu for final energy industry demand. 


\section{A.2 Dynamic IO Model Updating}

The main body of the report proposes that the RAS approach be used to provide a dynamic nature to the hybrid IO model. An example provided by Miller and Blair (2009) steps through the RAS procedure for updating a single direct input coefficient. This would be analogous to a material efficiency strategy bringing about an improvement in an industry's use of a specific material. The following discussion illustrates the procedure for estimating the resulting changes on other direct input coefficients in the economy.

The example begins with the base-year matrix of direct input coefficients, $A(0)$, the matrix containing the updated coefficient, $K$, the updated direct input coefficients matrix, $\bar{A}(0)$, and total outputs, $\mathbf{x}(0)$ :

$$
\begin{gathered}
\mathrm{A}(0)=\left[\begin{array}{lll}
0.120 & 0.100 & 0.049 \\
0.210 & 0.247 & 0.265 \\
0.026 & 0.249 & 0.145
\end{array}\right] \mathrm{K}=\left[\begin{array}{ccc}
0 & 0 & 0 \\
0 & 0 & 0 \\
0.209 & 0 & 0
\end{array}\right] \quad \overline{\mathrm{A}}(0)=\left[\begin{array}{ccc}
0.120 & 0.100 & 0.049 \\
0.210 & 0.247 & 0.265 \\
0 & 0.249 & 0.145
\end{array}\right] \\
\mathbf{x}(0)=\left[\begin{array}{l}
421 \\
284 \\
283
\end{array}\right]
\end{gathered}
$$

The estimate of new direct input coefficients is calculated as

$$
\widetilde{\mathbf{A}}(1)=K+\hat{\mathbf{r}} \overline{\mathrm{A}}(0) \hat{\mathbf{s}}
$$

Where $\hat{\mathbf{r}}$ is a diagonal matrix of elements modifying rows and $\hat{\mathbf{s}}$ is a diagonal matrix of elements modifying columns. The new row and column margins, $\overline{\mathbf{u}}(0)$ and $\overline{\mathbf{v}}$, respectively, are calculated by netting out the interindustry flows from the new coefficient.

Miller and Blair (2009) show the RAS approach estimates new direct input coefficients of

$$
\widetilde{\mathbf{A}}(1)=\left[\begin{array}{ccc}
0.2909 & 0.1892 & 0.2431 \\
0.0963 & 0.0884 & 0.2486 \\
0.209 & 0.0992 & 0.1514
\end{array}\right]
$$

